\title{
UTILIZAÇÃO E QUALIDADE DA INFORMAÇÃO CONTÁBIL NA PERCEPÇÃO DOS GESTORES DE EMPRESAS DE PEQUENO PORTE DE TRÊS LAGOAS
}

\author{
Marco Aurélio Batista de SOUSA ${ }^{1}$ \\ Ana Júlia Moreno CALVO
}

\begin{abstract}
${ }^{1}$ Professor do Curso de Ciências Contábeis da Universidade Federal de Mato Grosso do Sul, Campus de Três Lagoas (UFMS-CPTL). E-mail: marcoa.sousa@ufms.br

${ }^{2}$ Acadêmica do Curso de Engenharia da Produção e Bolsista PIBIC (2014/2015) da Universidade Federal de Mato Grosso do Sul, Campus de Três Lagoas (UFMS-CPTL).E-mail: ana_julia_aj@hotmail.com
\end{abstract}

Recebido em: 22/10/2015 - Aprovado em: 14/07/2016 - Disponibilizado em: 18/12/2016

\begin{abstract}
RESUMO
Esta pesquisa buscou verificar a utilização e a qualidade da informação contábil com base na percepção dos gestores de empresas de pequeno porte do setor varejista, instaladas no Município de Três Lagoas, Mato Grosso do Sul, no que tange à administração do seu negócio. Para tanto, esta pesquisa foi dividida em duas etapas: a primeira destinou-se à parte introdutória, pontuando questões relevantes ao seu desenvolvimento, seguido pela revisão da literatura contemplando assuntos pertinentes ao tema, os quais darão sustentação à parte prática; a segunda, por sua vez, foi operacionalizada por meio de um estudo exploratório do tipo survey, buscando estabelecer relações entre o referencial teórico do estudo e a realidade dos gestores das empresas a serem investigadas. Para coletar os dados necessários à sua execução foi utilizado questionário, com questões predominantemente fechadas e direcionados aos gestores das empresas, utilizando-se, para sua análise, a abordagem qualitativa. Os resultados do estudo demonstram que o objetivo principal da contabilidade não está sendo atingido em sua plenitude, uma vez que não atende ao gestor no que tange a sua tomada de decisão.

Palavras-chave Utilização e qualidade da informação. Informação contábil. Gestores. Empresas de pequeno porte. Três Lagoas.
\end{abstract}

\section{USE AND QUALITY OF ACCOUNTING INFORMATION IN THE PERCEPTION OF SMALL BUSINESS MANAGERS OF TRÊS LAGOAS}

\begin{abstract}
This research aimed to verify the use and the quality of accounting information based on the perception of managers of small businesses in the retail sector, installed in the city of Três Lagoas, Mato Grosso do Sul, with respect to the administration of your business. To this end, this research was divided into two stages: the first was assigned to the introduction, analyzing relevant issues for its development, followed by literature covering topics relevant to the theme, which will support the practical part; the second was operationalized through an exploratory study of the survey type, seeking to establish relations between the theoretical framework of the study and the reality of the managers of companies to be investigated. To collect the data necessary for the execution was used questionnaire with predominantly closed questions, targeted to managers of enterprises, using, to its analysis, the qualitative approach. The study results show that the main purpose of accounting is not being achieved in its fullness, as it does not comply with the manager when it comes to their decision making.

Keywords: Use and quality of information. Accounting information. Managers. Small business. Três Lagoas.
\end{abstract}




\section{INTRODUÇÃO}

A Contabilidade está diretamente associada à evolução da sociedade, principalmente no que reporta ao seu patrimônio, uma vez que "as preocupações com as propriedades e a riqueza é uma constante", e o acompanhamento e a evolução do patrimônio das pessoas e/ou organizações de qualquer natureza constituem o fator mais importante da evolução da disciplina contábil (IUDÍCIBUS, 2010, p.16). Para tanto, a contabilidade "coleta todos os dados econômicos mensurando-os monetariamente, registrando-os sumarizando-os em forma de relatórios ou de comunicados, que contribuem sobremaneira para a tomada de decisões" (IUDÍCIBUS e MARION, 2011, p. 19).

Fato que, para Iudícibus, Marion e Faria (2009, p. 33), resulta no objetivo principal da contabilidade, ou seja: "fornecer informações estruturadas de natureza econômica, financeira e, subsidiariamente física, de produtividade e social, aos usuários internos e externos à entidade objeto da contabilidade". Neste sentido, a informação é o elemento principal, na qual a contabilidade tem que se preocupar, e o seu valor, para Padoveze (2004, p. 50), deve estar relacionado com "a redução da incerteza no processo de tomada de decisão; a relação do benefício gerado pela informação versus o custo de produzi-la; o aumento da qualidade da decisão". Além disso, as informações possuem características que devem ser observadas, conforme apresenta o Quadro 1.

Quadro 1: Características genéricas da informação
\begin{tabular}{|c|l|}
\hline Autores & Características da boa informação \\
\hline $\begin{array}{c}\text { Freitas } \\
(1997)\end{array}$ & $\begin{array}{l}\text { Precisas, completa, econômica, } \\
\text { flexível, confiável, tempestiva, } \\
\text { adequada, frequente, válida, atual. }\end{array}$ \\
\hline $\begin{array}{c}\text { Strassburg } \\
(2004)\end{array}$ & $\begin{array}{l}\text { Útil, gerenciável, oportuna, atender } \\
\text { as necessidades, permitir análise, ter } \\
\text { limites, contextualizadas, } \\
\text { comparável, servir de apoio à tomada } \\
\text { de decisão. }\end{array}$ \\
\hline $\begin{array}{c}\text { Padoveze } \\
(2009)\end{array}$ & $\begin{array}{l}\text { Uniforme, precisa, atual, objetiva, } \\
\text { oportuna, integra, com conteúdo, } \\
\text { flexível, confiável, seletiva, } \\
\text { consistência. }\end{array}$ \\
\hline $\begin{array}{l}\text { Stair e } \\
\text { Reynolds } \\
(2011)\end{array}$ & $\begin{array}{l}\text { Precisas, completas, econômicas, } \\
\text { flexíveis, confiáveis, relevante, } \\
\text { simples, apresentadas no momento } \\
\text { exato, verificáveis, acessíveis e e } \\
\text { seguras. }\end{array}$ \\
\hline
\end{tabular}

Fonte: Elaborado pelos autores

Embora estas características possam ser generalizadas a todo o tipo de informações e usuários, há de se atentar para a pretensão de quem irá utilizá-las, os quais irão conferir outros atributos afeitos a ela, em função de seu contexto.

Em contabilidade, a informação é gerada para atender "pessoas ou entidades que necessitam de alguma informação contábil para tomada de decisões" (FAVERO, 2011, p. 2). Desempenha "um papel importante, de modo que é impossível ignorar sua participação na determinação das escolhas realizadas pela contabilidade e nas próprias opções feitas pelo contador" (NIYAMA e SILVA, 2011, p. 1).

De forma mais específica, estes usuários são classificados em: usuários internos e usuários externos. Entende-se por 
usuários internos "aqueles que trabalham na empresa e ocupam cargos que requerem a tomada de decisões, para tanto, precisam de informações direcionadas de acordo com suas necessidades". E, usuários externos "são aqueles que não possuem relação de trabalho com a empresa, mas necessitam de informações para a tomada de decisão" (FAVERO, ET. AL., 2011, p. 3).

Enquanto os usuários internos necessitam de informações que tratam da operacionalidade da organização, podendo a contabilidade atendê-los de forma mais específica quanto às suas reais necessidades, os usuários externos, por sua vez, buscam informações pontuais, referentes ao giro dos negócios da organização, de seu interesse, preocupados com a capacidade de geração de caixa e sua rentabilidade. No entanto, apesar de diferentes propósitos, pode-se, assim dizer, quanto à informação contábil, o profissional em contabilidade deve "levar em consideração a condição do usuário em compreendê-las, ou seja, a comunicação entre o contador e o usuário é fundamental neste processo" (FAVERO, ET. AL. 2011, p. 3).

Esta preocupação com questões que envolvem o processo de comunicação irá contribuir para que a informação contábil possa melhor atender seus usuários, mediante as suas características qualitativas "propriedades da informação que são necessárias para torná-las úteis"
(HENDRIKSEN e VAN BREDA, 2009, p. 95), conforme mostra o Quadro 2.

\begin{tabular}{|c|c|}
\hline \multicolumn{2}{|c|}{$\begin{array}{l}\text { Quadro 2: Características das informações } \\
\text { contábeis. }\end{array}$} \\
\hline Autores & $\begin{array}{c}\text { Características da informação } \\
\text { contábil }\end{array}$ \\
\hline $\begin{array}{l}\text { Financial } \\
\text { Accounting } \\
\text { Standards Board } \\
\text { - FASB (1980) }\end{array}$ & $\begin{array}{l}\text { Relevância, confiabilidade, } \\
\text { comparabilidade, uniformidade e } \\
\text { consistência. }\end{array}$ \\
\hline Padoveze (2009) & $\begin{array}{l}\text { Trazer mais benefícios que o } \\
\text { custo de obtê-la, compreensível, } \\
\text { utilidade, relevância, } \\
\text { confiabilidade e consistência. }\end{array}$ \\
\hline $\begin{array}{l}\text { Iudícibus, Marion } \\
\text { e Faria (2009) }\end{array}$ & $\begin{array}{l}\text { Compreensibilidade, relevância, } \\
\text { confiabilidade } \\
\text { comparabilidade. }\end{array}$ \\
\hline $\begin{array}{l}\text { Iudícibus } \quad(2009, \\
\text { p. 65) }\end{array}$ & $\begin{array}{l}\text { Tempestividade, integridade, } \\
\text { confiabilidade, comparabilidade, } \\
\text { compreensibilidade. }\end{array}$ \\
\hline $\begin{array}{l}\text { Resolução CFC } \\
\mathrm{n}^{\circ} .1 .374 / 2011\end{array}$ & $\begin{array}{l}\text { Relevância, } \\
\text { representação, } \\
\text { comparabilidade, } \\
\text { verificabilidade, tempestividade } \\
\text { e compreensibilidade. }\end{array}$ \\
\hline
\end{tabular}

Fonte: Elaborado pelos autores

Para o FASB (1980), a relevância que a informação deve ter para os seus usuários e a sua confiabilidade são consideradas qualidades primárias à informação contábil, enquanto a comparabilidade, que é o aspecto que possibilita a sua comparação com outros períodos, a uniformidade de sua exposição e conteúdo e a sua consistência, seriam secundárias.

Assim, tendo como base estas características, o Conselho Federal de Contabilidade, órgão que regula as atividades do profissional em contabilidade no país, com a resolução 1.374/11 estabeleceu como qualidades fundamentais à informação contábil: a relevância (capacidade de influenciar as decisões); a materialidade 
(divulgar somente questões dignas de atenção, a fim de não desperdiçar tempo e recursos em sua elaboração e divulgação); a representação fidedigna (que tem relação com sua veracidade e flexibilidade) e qualidades de melhoria a esta informação, como: a comparabilidade (possibilidade de acompanhar a evolução das demonstrações contábeis); a verificabilidade (conferir as suas fontes); a tempestividade (oportunidade, necessidade da informação naquele momento), e a compreensibilidade (relação com o entendimento dos usuários).

Diante destes comentários, este trabalho pretende analisar a utilização e qualidade da informação contábil na percepção dos gestores de empresas de pequeno porte de Três Lagoas.

\section{MATERIAL E MÉTODOS}

A pesquisa científica, de acordo com o entendimento de Trujillo Ferrari (1982, p. 180), "é uma atividade humana cujo propósito é descobrir respostas para as indagações significativas que são propostas". Com esta intenção, ela se utiliza de métodos e técnicas como procedimentos metodológicos que, embora não sejam condições suficientes para o seu sucesso, é uma condição necessária para diferenciá-la de outras pesquisas (ASTI VERA, 1989).

Desde modo, esta pesquisa se caracterizada primeiramente como exploratória, ao buscar "desenvolver, esclarecer e modificar conceitos e ideais a fim de fornecer hipóteses pesquisáveis para estudos posteriores" (TRUJILLO FERRARI, 1982, p. 180). E também, no segundo momento, ela é descritiva por observar, registrar, e analisar e correlacionar fatos, fenômenos, ou mesmo situações, sem a pretensão de manipulá-los (GIL, 2012). Dentro dos preceitos de um estudo desta natureza, optou-se em dividi-lo em duas etapas, a saber: a primeira, pesquisar os assuntos contemplados neste trabalho por meio de artigos e textos já produzidos e publicados (pesquisa em fontes secundárias); e a segunda um estudo do tipo survey, a fim de obter dados e informações sobre características, ações ou opiniões de determinado grupo de pessoas, utilizando-se de instrumentos de pesquisas como o questionário.

Quanto à abordagem do problema, o trabalho apresenta aspectos qualitativos, por descrever, analisar a interação das variáveis, compreender e classificar processos dinâmicos vivenciados por grupos sociais, contribuir no processo de mudança, criação ou formação de opiniões de grupos e possibilitar o entendimento das particularidades das pessoas (RICHARDSON, 1999).

Para coletar os dados utilizou-se de questionário com questões predominantemente fechadas, a fim, de facilitar a sua tabulação e análise, direcionado 
ao gestor das empresas, objetos de análises, sendo preenchido pelo acadêmico pesquisador o qual poderá também identificar in loco as condições do negócio além de obter mais informações a respeito do fenômeno observado e uma aproximação com o gestor e das dificuldades por ele enfrentadas.

Ademais, ressalta que a população, alvo deste estudo, compreendeu as empresas de pequeno porte de um determinado setor varejista da Cidade de Três Lagoas, Mato Grosso do Sul, ainda a ser definido. A escolha das empresas de pequeno porte como objeto de análise da pesquisa se deve em primeiro lugar, por sua representatividade na economia brasileira são mais de 6,3 milhões de estabelecimentos, contribuindo para a geração de empregos, tributos, produção e comercialização de bens e serviços (SEBRAE, 2013). E por ser possível de se verificar, com frequência que estas empresas têm falido ou enfrentam sérios problemas de sobrevivência, sendo uma tendência o encerramento de suas atividades nos primeiros anos de sua existência (IUDÍCIBUS e MARION, 2011).

Em função da quantidade de empresas de pequeno porte, espalhadas por todas as regiões do país e pela impossibilidade e complexidade que envolveria uma pesquisa com esta amplitude em termos de custos e tempo, optou-se em direcionar este estudo nas empresas de pequeno porte localizadas em Três Lagoas, Mato Grosso do Sul que enfrentam a mesma problemática em termos de gestão e sobrevivência em relação às outras regiões do país, segundo fontes do Serviço Brasileiro de apoio às Micro e Pequenas Empresas (SEBRAE, 2013). Iniciativa que corresponde a um tipo de amostra, um subconjunto da população, em que se pode estimar as suas características, realizada pela acessibilidade dos elementos a que se teve acesso, admitindo que estes representem, de alguma forma, a população estudada (GIL, 2012).

A escolha de Três Lagoas para a realização desta pesquisa é proposital, em função, principalmente, da acessibilidade das empresas de pequeno porte, pela parceria com o SEBRAE Costa Leste, para melhor definir quais empresas serão pesquisadas e qual o será o setor varejista. Além do fato de que tanto o acadêmico pesquisador quanto $\mathrm{o}$ orientador residir, trabalhar e estudar na cidade.

\section{RESULTADOS E DISCUSSÃO}

Os resultados e discussões do trabalho foram divididos com base no instrumento de pesquisa (questionário) direcionados aos proprietários e gestores das empresas pesquisadas. Sendo assim, inicialmente apresenta o perfil dos respondentes e as características das empresas. Posteriormente evidenciam-se os resultados pertinentes aos questionamentos feitos com base na relação das empresas com o escritório de 
contabilidade; os relatórios e informes contábeis utilizados. E, por fim, tem-se o resultado das características atribuídas pelos empresários à informação contábil.

\section{Perfil dos respondentes e características das} empresas pesquisadas

Os respondentes ao instrumento de pesquisa caracterizam-se, em sua maioria como sendo do sexo masculino, proprietários das empresas e com formação superior. Em relação às empresas pesquisadas, elas se caracterizam como sendo de pequeno porte (micro e pequena empresa), são constituídas, em sua maioria por um único proprietário $62 \%$, possuem entre 1 a 75 colaboradores, sendo que a maioria delas $88 \%$ possui menos de 20 funcionários. Atuam em diferentes setores da economia, como: alimentício; transporte; comércio diversificado; saúde; materiais de construção; prestação de serviço e educação.

Relação dos clientes com a empresa prestadora de serviços contábeis

Verificou-se que o tempo em que os gestores são clientes da organização contábil, coincide com sua própria existência, o que já demonstra, de certa forma, a confiança e a satisfação nos serviços que lhes são oferecidos pela organização. A respeito destes serviços, solicitou-se aos respondentes que pontuassem aqueles que são utilizados em seu negócio, identificados no Quadro 3.

Quadro 3: Serviços utilizados pelas empresas pesquisadas.

\begin{tabular}{|c|c|}
\hline Serviços & Total de Clientes \\
\hline Imposto de renda & 49 \\
\hline Escrita fiscal & 48 \\
\hline Departamento de pessoal & 50 \\
\hline Relatórios contábeis & 33 \\
\hline Planejamento tributário & 22 \\
\hline Consultoria & 19 \\
\hline Auditoria contábil & 1 \\
\hline
\end{tabular}

Fonte: Dados da pesquisa

Dentre os mais utilizados estão aqueles descritos, por Lyra (2003) como sendo os principais, a saber: os relacionados ao departamento de pessoal, área fiscal e contábil.

Quanto à qualidade destes serviços, (36) respondentes consideram os serviços oferecidos pela empresa contábil, na qual eles são clientes, como satisfatórios às suas necessidades, enquanto (7) relataram que estes mesmos serviços excedem às suas expectativas de informação, (2) mencionaram que estes serviços satisfazem parcialmente suas necessidades e, para (5), eles deixam a desejar.

\section{Relatórios e informações contábeis}

Os relatórios contábeis, segundo o entendimento de Thomé (2001, p. 95), é “o resultado final de todo o trabalho executado referente a uma determinada tarefa, na sua forma material, palpável". Por meio destes documentos, os gestores devem avaliar a evolução de seus negócios, planejá-los e tomar decisões. 
Tendo como base tais aspectos, os questionamentos feitos aos clientes da empresa contábil buscaram demonstrar quais os relatórios que eles utilizam em seus negócios, como eles os qualificam, se as informações contidas nestes documentos são úteis e qual a finalidade destas informações e, por fim, se eles estão satisfeitos com o conteúdo e com a forma que estas informações estão sendo a eles disponibilizadas.

Em relação aos relatórios, dos (50) clientes pesquisados, o mais utilizado é o Balanço Patrimonial (29), seguido pela Demonstração do Resultado de Exercício (26) clientes, Demonstração do Fluxo de Caixa, (14) clientes; Demonstração das Mutações Patrimoniais (1). Os respondentes puderam assinalar mais que um relatório, enquanto outros não quiseram opinar sobre esta questão.

Quanto à qualidade destes relatórios, (19) clientes os qualificam como excelentes, enquanto para (23) eles são bons, (3) mencionaram ser ruins e (2) razoáveis, enquanto outros participantes da pesquisa não quiseram opinar sobre esta questão. Em relação à utilização das informações, (42) pessoas mencionaram que elas são úteis aos seus negócios, mas, para (7) respondentes elas não têm utilidade, e (1) uma pessoa não opinou sobre o assunto.

Daqueles que consideram ser úteis as informações aos seus negócios, destacam que estas informações são utilizadas para os seguintes fins conforme mostra o Quadro 4.

Quadro 4: Finalidade das informações contábeis segundo as empresas pesquisadas.

\begin{tabular}{|l|c|}
\hline Finalidade das informações contábeis & $\begin{array}{c}\text { Total de } \\
\text { clientes }\end{array}$ \\
\hline Para fins fiscais (atender a legislação) & 38 \\
\hline Para a tomada de decisão & 29 \\
\hline $\begin{array}{l}\text { Para fins gerenciais (atender às } \\
\text { necessidades internas da gestão da } \\
\text { empresa) }\end{array}$ & 25 \\
\hline
\end{tabular}

Fonte: Dados da pesquisa

Os resultados evidenciados neste quadro vêm corroborar com outros estudos e pesquisas, tais como a de Miranda et. al. (2008); Stroeher e Freitas (2008) e Amorim e Silva (2012), que atestam que principalmente as micro e pequenas empresas se utilizam da informação contábil prioritariamente para fins fiscais e tributários. Após atender a esta finalidade, (29) respondentes também mencionaram utilizá-la para a tomada de decisão, e (25) também a utilizam para fins gerenciais.

Quanto à satisfação das informações que são geradas pela empresa contábil, clientes pesquisados (41) relataram estar satisfeitos quanto ao seu conteúdo e a forma como elas estão sendo evidenciadas, no entanto, (8) respondentes mencionaram que elas deixam a desejar.

\section{CARACTERÍSTICAS ATRIBUIDAS AS INFORMAÇÕES CONTÁBEIS}

Dentre estas características, as que obtiveram o maior número de indicações foram: útil com (40) indicações, confiável 
(39) e íntegra (30). Após associar estas características à qualidade da informação contábil, questionou-se aos respondentes a respeito das informações contábeis que são geradas e disponibilizadas a eles pela empresa prestadora de serviço, como eles qualificam estas informações. $\mathrm{O}$ resultado deste questionamento pode ser visualizado na Figura 1.

Figura 1: Características da informação contábil atribuídas aos serviços da empresa contábil



Fonte: Dados da pesquisa

A característica útil foi apontada como a mais importante por todos os respondentes, em relação à informação contábil que é gerada e disponibilizada pela empresa prestadora de serviços contábeis. Em seguida, (27) respondentes destacam que as informações atendem as suas necessidades e, para (25) respondentes elas são confiáveis, seguindo de (23) que dizem que elas são fornecidas no prazo e (22) precisas. Com menor representatividade aparecem as demais características.

\section{CONCLUSÕES}

Esta pesquisa teve como foco principal verificar a utilidade e a qualidade da informação contábil. A atenção dispensada à informação contábil, com este enfoque, buscou-se contribuir com mais elementos para se conhecer um pouco mais sobre a natureza do processo decisório destes usuários com estes tipos de informações, bem como sobre as características que melhor as qualificam.

Assim, tendo como referência os respondentes da pesquisa, apresentam-se os seguintes resultados. Em relação aos serviços, os mais utilizados pelos clientes são aqueles vinculados ao departamento de pessoal, parte fiscal e contábil. Primeiramente, o objetivo destas organizações é atender à legislação fiscal, contábil e trabalhista, sendo a qualidade destes serviços considerada boa pela maioria dos usuários pesquisados.

Quanto aos relatórios, verificou-se que os respondentes utilizam, com mais frequência, o Balanço Patrimonial e a Demonstração do Resultado do Exercício para acompanhar o seu patrimônio e $\mathrm{o}$ seu resultado, no período.

Como ocorre com os serviços utilizados pelos clientes, as informações contábeis apresentadas a eles são utilizadas, em sua maioria para atender à legislação fiscal e tributária, sendo que para alguns, elas também são consideradas no processo decisório e para fins gerenciais, sendo a qualidade do 
conteúdo destas informações perceptível por todos os respondentes.

No que se referem às informações contábeis, os clientes elencaram as características que eles julgam ser fundamentais para melhor qualificá-las, a saber: útil, confiável, íntegra, consistente, relevante, fidedigna, oportuna, comparável, compreensível e verificável. Por outro lado, quando estes respondentes foram convidados a indicar quais características qualitativas são perceptíveis às informações contábeis, geradas pela empresa prestadora de serviços contábeis, o resultado foi o seguinte: útil, atende às necessidades, confiável, fornecidas no prazo, precisa, íntegra, simples, completa, atual, consistente, apoio à tomada de decisão, permite análise, econômica, válida, gerenciável.

Vale destacar que tanto as características atribuídas, quanto as percebidas estão dispostas de acordo com a quantidade de indicações que receberam, sendo que as características útil, íntegra, confiável e consistente são comuns a ambas (atribuídas e percebidas).

Portanto, diante do exposto, observa-se que as percepções dos usuários da informação contábil, quanto à utilidade, qualidade e às características que melhor qualificam as informações geradas pela contabilidade, está relacionada com os serviços por eles utilizados, os relatórios solicitados e, principalmente, com as peculiaridades que envolvem os seus negócios.

\section{REFERÊNCIAS}

AMORIM, D. S; SILVA, A. C. R. Gestão estratégica da informação contábil: um enfoque no gerenciamento de micro e pequenas empresas. RIC - Revista de Informação Contábil. Vol. 6, n. 1, p. 39-65, jan./mar, 2012.

ASTI VERA, A. Metodologia da pesquisa científica. São Paulo: Globo, 1989.

\section{CONSELHO FEDERAL DE} CONTABILIDADE. Resolução CFC No. 1.374/2011: estrutura conceitual para a elaboração e divulgação de relatório contábilfinanceiro. Brasília: CFC, 2011.

FAVERO, H. L.; LONARDONI, M.; SOUSA. C.; TAKAKURA, M.

Contabilidade teoria e prática. 6 . d. São Paulo: Atlas, 2011.

FINANCIAL ACCOUNTING STANDARDS BOARD. Statement of Financial Accounting Concepts $\mathrm{n}^{\circ} 2$. Qualitative characteristics of accounting information. May 1980, 60p. Disponível em:

<http://www.fasb.org/cs/BlobServer?blobkey $=$ id\&blobwhere $=1175820900499 \&$ blobheade $\mathrm{r}=$ application $\% 2 \mathrm{Fpdf} \&$ blobcol=urldata\&blobt able=MungoBlobs $>$. Acesso em 5 de dezembro de 2013.

FREITAS, H. Informação e decisão: sistemas de apoio e seu impacto. Porto Alegre: Ortiz, 1997.

GIL, A. C. Como elaborar projeto de pesquisas. 6. ed. São Paulo: Atlas, 2012.

HENDRIKSEN, E. S; VAN BREDA, M. F. Teoria da contabilidade. São Paulo: Atlas, 2009.

IUDÍCIBUS, S. Teoria da contabilidade. 10. ed. São Paulo: Atlas., 2010. 
IUDÍCIBUS, S.; MARION, J. C.; FARIA, A. C. Introdução à teoria da contabilidade para o nível de graduação. 5. ed. São Paulo: Atlas, 2009.

LYRA, R. L. W. C. Uma contribuição à mensuração do resultado econômico da decisão de investimentos em qualidade em empresas de serviços contábeis: uma abordagem da gestão econômica. 120 f. 2003. Dissertação (Mestrado em Controladoria e Contabilidade) - Faculdade de Economia, Administração e Contabilidade (FEA), São Paulo, 2003.

MIRANDA, L. C; LIBONATI, J. J; FREIRE, D. R; SATURNINO, O. Demanda por serviços contábeis pelos mercadinhos: são os Contadores Necessários? Contabilidade Vista \& Revista. v. 19, n. 1, p. 131-151, jan./ mar, 2008.

NIYAMA, J. K.; SILVA, C. A. T. Teoria da contabilidade. 2. ed. São Paulo: Atlas, 2011.

PADOVEZE, C. L. Sistemas de informações contábeis: fundamentos e análise. $6^{\circ}$ São Paulo: Atlas, 2009.

RICHARDSON, R. J. Pesquisa social: métodos e técnicas. 3. ed. São Paulo: Atlas, 1999.

SERVIÇO BRASILEIRO DE APOIO ÀS MICRO E PEQUENAS EMPRESAS. Taxa de sobrevivência das empresas no Brasil: Coleção estudos e pesquisas. São Paulo: SEBRAE, 2013. Disponível em: <http://bis.sebrae.com.br/GestorRepositorio/ ARQUIVOS_CHRONUS/bds/bds.nsf/93772f 4f62b0716c573d3a9ed5a6a3aa/\$File/4456.pd f.> Acesso em 20 de abril de 2015

STAIR, R. M.; REYNOLDS, G. W.

Princípios de sistema de informação. 9. Ed.

Rio de Janeiro: LTC, 2011.

STRASSBURG, U. A contabilidade frente aos avanços tecnológicos. Cascavel:

EDUNIOESTE, 2004.
STROEHER, A. M.; FREITAS, H. O uso das informações contábeis na tomada de decisão em pequenas empresas. Revista de

Administração Eletrônica. São Paulo, v.1, n.1, art.7, jan./jun. p. 1-25, 2008.

THOMÉ, I. Empresas de serviços contábeis: estrutura e funcionamento- São Paulo : Atlas, 2001.

TRUJILLO FERRARI, A. Metodologia da pesquisa científica. São Paulo: McGraw-Hill do Brasil, 1982. 